Isadora Peres Klein ${ }^{1}$ Manoela Domingues Martins ${ }^{2}$ Marco Antonio Trevizani Martins $^{2}$ Manoel Sant'Ana Filho ${ }^{3}$ Pantelis Varvaki Rados ${ }^{3}$ Vinicius Coelho Carrard ${ }^{2}$

${ }^{1}$ Federal University of Rio Grande do Sul (Graduate student)

2 Ph.D./School of Denti try - Federal University of Rio Grande do Sul (Assistant Professor).

${ }^{3}$ Ph.D./School of Denti try - Federal University of Rio Grande do Sul (Associate Professor).

Declaration of Interests: The authors certify that they have no commercial or associative interest that represents a conflict of interest in connection with the manuscript.

Corresponding Author:

Vinicius Coelho Carrard.

E-mail: vinicius.carrard@ufrgs.br

DOI: $10.18762 / 2525-5711.20160010$

Submitted: August 14, 2012;

Accepted: June 27, 2013

Originally published as 1 (2) April/June 2012.

\section{Painful keratocystic odontogenic tumor due to secondary infection associated to pulp necrosis}

\section{ABSTRACT:}

The keratocystic odontogenic tumor (KCOT) is defined as a benign, odontogenic, uni- or multicystic intraosseous tumor with infiltrative behavior. KCOTs occur over a broad age range, predominantly in the second and third decades of life. This odontogenic tumor is usually asymptomatic and diagnosed incidentally on routine radiographs. Growth is typically medullary and there is no bone expansion in the majority of cases. In the present case, the patient exhibited pain and expansion of buccal cortical bone, unusual findings in this tumor. This could be related to pulp necrosis of the adjacent decayed tooth, leading to a secondary infection of the KCOT.These circumstances become the diagnosis difficult, because the clinical signals and symptoms strongly mimic an inflammatory lesion.

Keywords: odontogenic keratocyst; odontogenic tumors; recurrence. 


\section{INTRODUCTION}

The keratocystic odontogenic tumor KCOT, formerly known as the odontogenic keratocyst, was renamed in 2005 to better convey its neoplastic nature ${ }^{1}$. The KCOT is defined as a benign, odontogenic, uni- or multicystic intraosseous tumor with infiltrative behavior ${ }^{2,3}$. It is believed to arise from the dental lamina and account for approximately $28.11 \%$ of odontogenic tumors ${ }^{4}$.

KCOTs occur over a broad age range, predominantly in the second and third decades of life. They are slightly more common in white males and most frequently affect the mandible (65 to $83 \%$ of cases $)^{5,6}$. This odontogenic tumor is usually asymptomatic and diagnosed incidentally on routine radiographs. Growth is typically medullary and there is no bone expansion in the majority of cases ${ }^{1}$.

On plain radiographs, KCOTs appear as unilocular or multilocular radiolucencies, usually with sclerotic margins. KCOTs are associated with unerupted teeth in $25 \%$ a $40 \%$ of cases, and may be misdiagnosed as dentigerous cysts $^{5}$. However, other odontogenic lesions may present with similar features ${ }^{7}$.

\section{CASE REPORT}

A 31-year-old male noticed a facial swelling and pain on the lower left side. The patient reported a history of endodontic therapy of the left mandibular second molar and extraction of an impacted left mandibular third molar 10 years previously. Microscopic examination of material associated with the extracted third molar led to a diagnosis of dentigerous cyst. The patient was instructed to return for regular postoperative clinical and radiographic monitoring, but was lost to follow-up. Extraoral examination revealed facial swelling on the left with normal overlying skin. Examination of the oral cavity revealed a left-sided mass lesion, hard on palpation, with effacement of the mucobuccal fold and no signs of inflammation, extending from the mandibular second premolar to the mandibular second molar; the involved teeth were angled lingually (Figure 1). The left mandibular first molar was carious, with pulp necrosis, and unroofing of the pulp chamber had been performed. The patient reported purulent drainage when the pulp chamber was entered and later development of a fistula. Panoramic radiographs exhibited a well-defined multilocular radiolucency with sclerotic borders extending from distal to the left mandibular canine to the angle of the mandible (Figure 2). An incisional biopsy was performed and the specimen was sent for routine (hematoxylin and eosin staining) microscopic examination.
Stratified squamous epithelium with 8 to 10 cell layers thick, showing palisaded basal layer. The epithelial-connective tissue interface was flat. The wall was thin and composed by dense connective tissue (Figure 3). In this case, the left mandibular first and second molars were extracted because they are associated to the lesion. Enucleation of the lesion was performed, followed by curettage and cryotherapy, to mitigate the potential of recurrence while maintaining a minimally invasive approach. The patient is currently undergoing close clinical and radiological (Figure 4) monitoring and remained disease-free at 24-month follow-up.

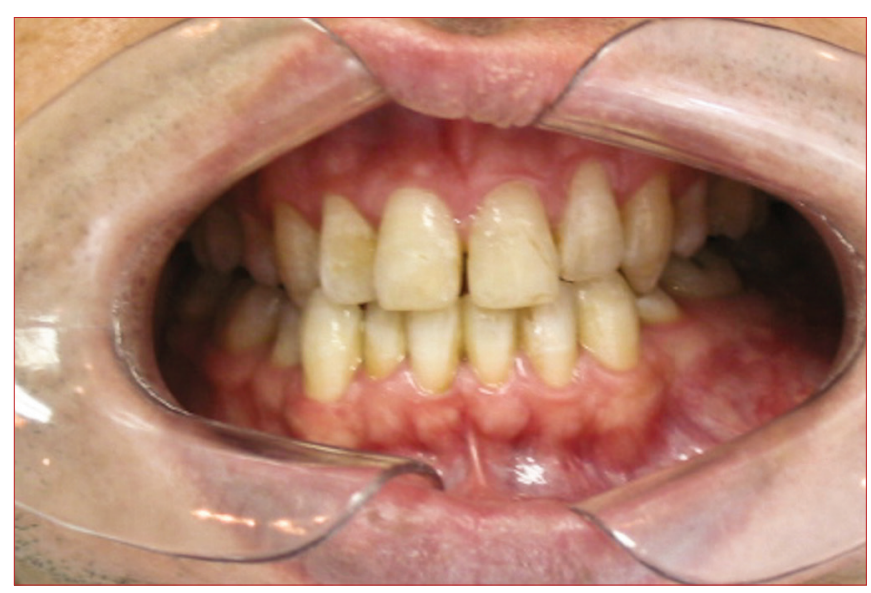

Figure 1. Mass lesion leading to effacement of the mucobuccal fold extending from the left mandibular second premolar to the left mandibular second molar.

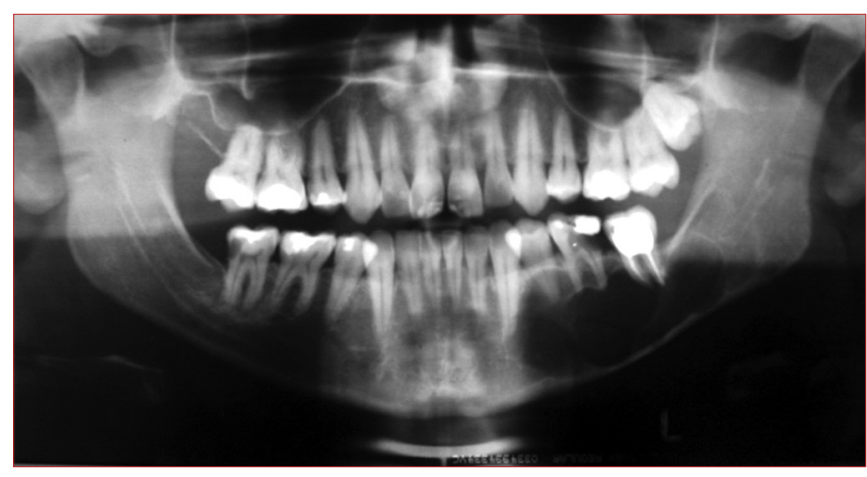

Figure 2. Panoramic radiograph exhibiting a multilocular radiolucency

\section{DISCUSSION}

Radiolucent bony lesions of the jaws may be of inflammatory, cystic, neoplastic, or reactive origin. Imaging findings should be evaluated in conjunction with clinical findings, in order to establish a differential diagnosis ${ }^{8}$. The main features that should be taken into account are the radiodensity, growth pattern, margins, and location of the lesion, as well as its relationship to adjacent teeth and neighboring structures ${ }^{9-13}$. 


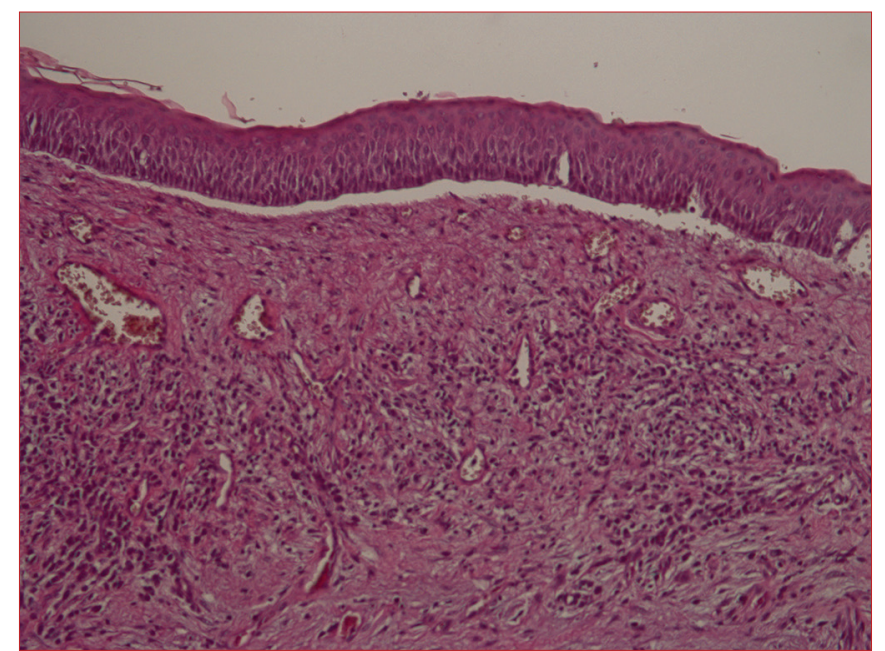

Figure 3. Photomicrograph of the lesion after partial biopsy (H\&E stain, original magnification $\times 200$ ).

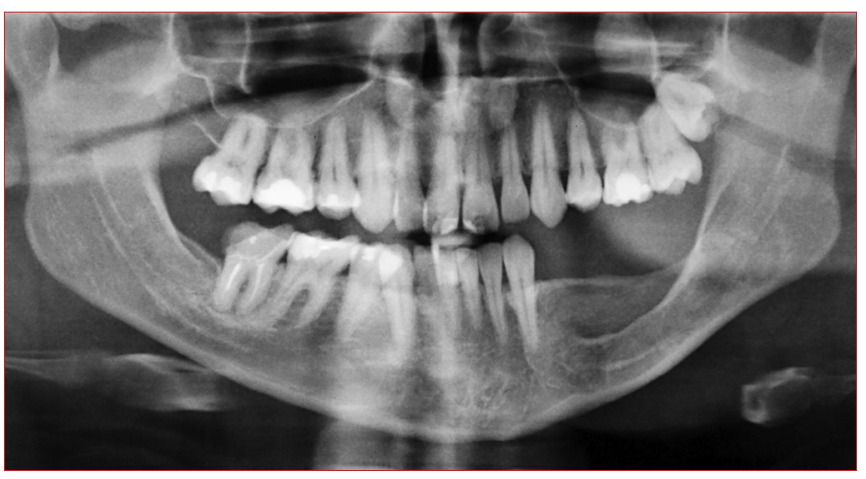

Figure 4. Follow-up panoramic radiograph of the patient taken 24 months after surgical remotion of the lesion, showing bone healing.

Unilocular radiolucency with well-circumscribed borders is usually indicative of benign, slow-growing lesions. Multilocular lesions with well-defined borders are also usually indicative of benign, but more aggressive, conditions ${ }^{8}$.

In the present case, the main diagnostic hypotheses were KCOT, ameloblastoma, and central giant cell lesion, due to the multilocular radiographic appearance of the lesion. These diagnostic hypotheses were based on history and behavior of the lesion, suggested by plain radiography findings. Another hypothesis was periapical cyst based in the fact that adjacent tooth exhibited pulp necrosis and the absence of lamina dura. Therefore, clinical and imaging aspects are not enough to establish a definitive diagnosis in such lesions, and incisional biopsy followed by microscopic examination of the specimen is mandatory.

Several treatment options have been proposed and discussed, with recurrence rates ranging from 5 to $62 \%$. More conservative modalities, such as enucleation followed by application of Carnoy's solution or cryotherapy and marsupialization followed by enucleation are recommended by some authors. However, these approaches should be used in a select group of cooperative patients, as they require regular long-term follow-up ${ }^{14,15}$. Surgical resection is a more aggressive treatment option and carries a lower recurrence rate, but can be mutilating with extensive lesions. The likelihood of recurrence is associated with a variety of factors, such as lesion size and site, presence of associated teeth, and presence or history of secondary infection. The optimal treatment modality and prognosis must be determined on a case-by-case basis ${ }^{2}$. The tumor may recur several years after treatment; long-term clinical and radiographic follow-up, of at least 5 years duration, is of the essence ${ }^{2,3,16}$.

In the present case, the patient exhibited pain and expansion of buccal cortical bone, unusual findings in this tumor ${ }^{1}$. This could be related to pulp necrosis of the adjacent decayed tooth, leading to a secondary infection of the KCOT.These circumstances become the diagnosis difficult, because the clinical signals and symptoms strongly mimic an inflammatory lesion ${ }^{1}$. In this case, enucleation of the lesion was performed, followed by curettage and cryotherapy and the patient is being submitted to strict follow up.

\section{CONCLUSION}

Multilocular radiolucency of the mandible with periapical involvement can mimic a variety of lesions with different origins, natural histories, and management options. This case report highlights the need for careful clinical assessment, imaging, biopsy, and microscopic examination in order to establish the proper diagnosis and, consequently, define the optimal course of treatment and clinical and radiographic follow-up.

\section{ACKNOWLEDGMENT}

The authors would like to thank to Dr. Jorge Manfrin and to Dr. Fernando Amaral for the assistance on surgical procedure.

\section{REFERENCES}

1. Barnes L EJ, Reichart P, Sidransky D. World health organization classification of tumours: Pathology and genetics of head and neck tumours. Lyon: IARC Press, 2005.

2. Madras J, Lapointe H. Keratocystic odontogenic tumour: Reclassification of the odontogenic keratocyst from cyst to tumour. Tex Dent J. 2008;125(5):446-54.

3. Kuroyanagi N, Sakuma H, Miyabe S, Machida J, Kaetsu A, Yokoi M, et al. Prognostic factors for keratocystic odontogenic tumor (odontogenic keratocyst): Analysis of clinico-pathologic and immunohistochemical findings in cysts treated by enucleation. J Oral Pathol Med. 2009;38(4):386-92. DOI: http://dx.doi.org/10.1111/j.16000714.2008.00729.x 
4. Osterne RL, de Matos Brito RG, Negreiros Nunes Alves AP, Cavalcante RB, Sousa FB. Odontogenic tumors: A 5-year retrospective study in a Brazilian population and analysis of 3406 cases reported in the literature. Oral Surg Oral Med Oral Pathol Oral Radiol Endod. 2011;111(4):474-81. DOI: http://dx.doi.org/10.1016/j. tripleo.2010.10.018

5. Thompson LDR. Head and neck pathology: a volume in the series foundations in diagnostic pathology. London: Churchill Livingstone; 2006.

6. Brannon RB. The odontogenic keratocyst: A clinicopathologic study of 312 cases. Part I. Clinical features. Oral Surg Oral Med Oral Pathol. 1976;42(1):54-72. DOI: http://dx.doi.org/10.1016/00304220(76)90031-1

7. Maurette PE, Jorge J, de Moraes M. Conservative treatment protocol of odontogenic keratocyst: A preliminary study. J Oral Maxillofac Surg. 2006;64(3):379-83. DOI: http://dx.doi.org/10.1016/j. joms. 2005.11.007

8. Martins MAT, Lascala, CA, Martins MD, Ferreira ETT.The importance of periapical radiograph in the diagnosis of intra-osseous lesions of the jaws: Review of the literature. Revista da ABRO. 2007;25-31. (in portuguese)

9. Ledesma-Montes C, Hernández-Guerrero JC, Garcés-Ortíz M. Clinico-pathologic study of odontogenic cysts in a Mexican sample population. Arch Med Res. 2000;31:373-6. DOI: http://dx.doi. org/10.1016/S0188-4409(00)00069-2
10. Mosqueda-Taylor A, Irigoyen-Camacho ME, Diaz-Franco MA, Torres-Tejero MA. Odontogenic cysts. Analysis of 856 cases. Med Oral. 2002;7:89-96.

11. Ochsenius G, Escobar E, Godoy L, Peñafiel C. Odontogenic cysts: analysis of 2,944 cases in Chile. Med Oral Patol Oral Cir Bucal. 2007; 12:E85-91

12. Nary Filho H, Matsumoto MA, Fraga SC, Gonçales ES, Sérvulo F. Periapical radiolucency mimicking an odontogenic cyst. Int Endod J. 2004;37:337-44. DOI: http://dx.doi.org/10.1111/j.01432885.2004.00801.x

13. Garcia-Pola MJ, Gonzalez M, Lopez JS. Odontogenic maxillary cyst: Clinicopathologic diagnostic and therapeutic considerations. Med Oral. 1997;2:219-241.

14. Pogrel MA, Jordan RC. Marsupialization as a definitive treatment for the odontogenic keratocyst. J Oral Maxillofac Surg. 2004;62(6):651-5; discussion 55-6.

15. Tonietto L, Borges HO, Martins CA, Silva DN, Sant'Ana Filho M. Enucleation and liquid nitrogen cryotherapy in the treatment of keratocystic odontogenic tumors: A case series. J Oral Maxillofac Surg. 2011;69(6):e112-7. DOI: http://dx.doi.org/10.1016/j. joms.2010.12.032

16. Boffano P, Ruga E, Gallesio C. Keratocystic odontogenic tumor (odontogenic keratocyst): preliminary restrospective review of epidemiologic, clinical, and radiologic features of 261 lesions from University of Turin. J Oral Maxillofac Surg. 2010;68:2994-9. DOI: http://dx.doi.org/10.1016/j.joms.2010.05.068 